\begin{tabular}{|c|c|c|}
\hline ב & International Journal of Current Research in & \\
\hline & Biosciences and Plant Biology & $\div 33^{\circ}$ \\
\hline $\begin{array}{l}\text { EXCELLENT } \\
\text { PUBLISHERS } \\
\end{array}$ & $\begin{array}{c}\text { ISSN: 2349-8080 (Online) • Volume } 3 \bullet \text { Number } 5 \text { (May-2016) } \\
\text { Journal homepage: } \underline{\text { www.ijcrbp.com }}\end{array}$ & \\
\hline
\end{tabular}

\title{
Antidermatophytic Potential of Selected Medicinal Plants against Microsporum Species
}

\author{
G. Krishnaveni ${ }^{1,2}$, C. Banu Rekha ${ }^{2 *}$, P. Rajendran², V. Nithyakalyani² and P. Vithiyavani \\ ${ }^{1}$ Research \& Development Centre, Bharathiar University, Coimbatore-641 046, Tamil Nadu, India \\ ${ }^{2}$ Department of Microbiology, Dr. MGR Janaki College of Arts \& Science for Women, Chennai-6oo o28, Tamil Nadu, India \\ *Corresponding author.
}

\begin{abstract}
Leaf extracts of Cymbopogon citratus (lemon grass) and bulb extracts of Allium sativum (garlic) extracted with various solvents (ethanol, ethyl acetate and aqueous for Cymbopogon citratus, and ethyl acetate chloroform and aqueous for Allium sativum) were evaluated for antidermatophytic activity against Microsporum spp. isolated from different water samples. Out of a total of 60 water samples analysed, 19, 18, 9, 6 and 4 samples showed Microsporum canis, Microsporum gypseum, Microsporum nanum, Microsporum persicolor and Microsporum audouinii respectively. For the present study, Microsporum gypseum and Microsporum canis were used to find out the antidermatophytic activity of the extracts since they were found to be predominant in the water samples analysed. Minimum Inhibitory Concentration (MIC) and Minimal Fungicidal Concentration (MFC) were found out with different solvent extracts of Allium sativum and Cymbopogon citratus and combination of Allium sativum and Cymbopogon citratus extracts which showed best activity when tested individually. Ethyl acetate leaf extract of Cymbopogon citratus and Allium sativum showed the inhibitory activity against Microsporum canis and Microsporum gypseum. Microsporum canis was inhibited by chloroform extract of Allium sativum at a concentration of $250 \mu \mathrm{g} / \mathrm{ml}$, whereas ethyl acetate and aqueous extract showed inhibition at $125 \mu \mathrm{g} / \mathrm{ml}$ and $500 \mu \mathrm{g} / \mathrm{ml}$ respectively. The ethyl acetate leaf extract of Cymbopogon citratus showed the lowest inhibition concentration of $62.5 \mu \mathrm{g} / \mathrm{ml}$ against Microsporum canis, followed by ethanolic leaf extract $(250 \mu \mathrm{g} / \mathrm{ml})$ and aqueous leaf extract $(1000 \mu \mathrm{g} / \mathrm{ml})$. The combined ethyl acetate extracts of Cymbopogon citratus leaves and Allium sativum bulb recorded the lowest inhibitory concentration of 62.5 $\mu \mathrm{g} / \mathrm{ml}$ against Microsporum spp. The combinations of extracts have greater inhibitory activity against Microsporum species tested.
\end{abstract}

\section{Introduction}

A skin infection due to dermatophytes has become a significant health problem affecting children, adolescents and adults. The cutaneous fungal infections of man includes a wide variety of diseases in which the integuments and its appendages the hair and nail are involved. The mycoses are caused by approximately 20

\section{Article Info}

Accepted: 22 April 2016

Available Online: 06 May 2016

\section{Keywords}

Antifungal activity

Dermatophytes

Medicinal plants

Microsporum canis

Microsporum gypseum 
than $20-25 \%$ of the world's population. Their etiological agents and predominating anatomical infection patterns vary with geographical location and environmental and cultural factors. Such fungi grow at surface temperatures of $25^{\circ} \mathrm{C}-28^{\circ} \mathrm{C}$ with warm and humid conditions which is supported for infection on human skin. Infections by fungi are relatively common in tropical countries due to wearing of dirty and pungent clothing, low socioeconomic status, crowded living conditions, superficial skin infections, a low tendency to self limitation and poor medical care help to increase the epidemic spread of skin mycoses. Also, booming tourism, international sports activities and increasing migration are responsible for disseminating an imported fungal group of mycoses (Ajello et al., 1974).

Dermatophytosis is often connected with epidemiological circumstances promoting reinfection. For example, Microsporum canis commonly indicates a cat (rarely a dog) as a persistent inoculum source, while Microsporum gypseum causing similar lesions, and indicates contact with contaminated soil. An outbreak of Microsporum audouinii infection in school may indicate inoculum from an index patient who has recently travelled from the first endemic area such as central Africa. In various cases, sources of potentially reinfective inoculam must be dealt within dermatophytosis or else therapy runs a high risk of proving futile (Barisic Drusko et al., 2008).

Fungi have been categorized like an individual kingdom ever since the 1960s. They embrace to yeast and moulds which are diverse in morphological and physiological appearance. They may populate sexually, asexually or both. In dermatophytic fungi, some species of Microsporum and Trichophyton genera potentially produced perfect stage of fungi as the ascomata with asci and ascospores through sexually reproduction. From all pathogenic fungi, few have ability to penetrate the natural keratin and play a role as the keratinolytic agent. Emmons (1934) was the first individual who sited to dermatophytes into three anamorphic (asexual, imperfect) genera, Epidermophyton, Microsporum and Trichophyton. These organisms are pathogenic members of the keratinophilic (keratin digesting) soil fungi. Few species of these genera also have the capability of reproducing sexually similar as Teleomorphic genus Arthroderma of the Ascomycota phylum. Keratinophilic fungi are the finest keratin degraders, prevalent in keratin rich environments. The waste water and sewage are rich in organic matter, are habitat for many (Kacprzak et al., 2005) and domestic sewage is a rich source of keratin, cellulose and lignin, etc. where the occurrence of keratinophilic fungi can be easily expected. Nature has been a source of medicinal agents for thousands of years and since the beginning of man. Many of the plant species found that it can be used medically. Essential oils are aromatic substances which are obtained from various plant parts which exhibit antibacterial, antifungal, and antiviral activity. Different plant parts have been widely used for the preparation of folk remedies. Apart from leaves, fruits and seeds, inflorescence has also been screened for their antimicrobial properties. Green plants because of their vast diversities contain a wide spectrum of plant defense chemicals, most of which make vital contribution to the list of medicines for human even today. At the time of 2500-600 BC, large number of plants has been reported in Ayurvedic literature which possesses medicinal properties (Joshi, 2012). Studies also confirm that the combined activity of plant extracts exert good antimicrobial activity than individual extracts (Karmegam et al., 2008; Vigneshwari et al., 2014).

\section{Cymbopogon citratus (DC.) Stapf. (Lemon grass)}

Cymbopogon citratus (DC.) Stapf. commonly called lemon grass is an aromatic, perennial grass belonging to the family Gramineae. It is a tropical plant, grown as an ornamental in many temperate areas with maximum a height of about $1.8 \mathrm{~m}$ and its leaves $1.9 \mathrm{~cm}$ wide covered with a whitish bloom. Like other members of the genus, C. citratus, yields citral, a volatile oil with strong lemon fragrance. It is used in manufacture of perfumes, coloured soaps and synthesis of vitamin (Gunasingh and Nagarajan, 1981).

Lemon grass is also widely used in traditional medicine in Cuba and in many other countries of the Caribbean region. In certain medications, it is used for mental illness. It is an antifungal, antitoxicant and decolorizing agents. In combination with other herbs, it has large use as cure for Malaria (Gbile, 1986).

\section{Allium sativum L. (Garlic)}

Allium sativum $\mathrm{L}$. is a bulbous plant belonging to the lily family, Liliaceae. It is commonly known as garlic and is found in tropical countries. It contains aromatic sulphur based compounds, which contribute to the characteristic taste and odour. Allium sativum has been known to have inhibitory activity on various pathogenic bacteria, viruses and fungi. Antimicrobial activity of garlic is attributed to its key component allicin. Allicin is unstable, once it is generated it readily decomposes to produce diallyl 
sulphide, diallyl disulphide, diallyl trisulphide, allyl ethyl trisulphide, dithiis and ajoene. The present study was done to investigate the antidermatophytic activity of aqueous, ethanolic and methanolic extracts of garlic on some dermatophytes isolated from primary school children in Aba, Nigeria (Jaber and Al-Mossawi, 2007).

The objectives of the present study was to identify the presence of dermatophytes i.e., Microsporum spp. from different water from south Tamil Nadu, which causes infection to human beings and animals, and to find out the MIC and MFC of Allimum sativum bulb and Cymbopogon citratus leaf extracts against predominant Microsporum spp.

\section{Materials and methods}

\section{Sample collection}

The samples for the isolation of Microsporum spp. have been collected from various water sources in different places of Tamil Nadu. Totally 60 water samples were collected of which 25 from sewage water, 20 from swimming pool, 7 from ponds and 8 from lakes.

\section{Isolation and identification of Microsporum spp.}

The various water samples were serially diluted in the dilution of $10^{-1}, 10^{-2}, \ldots \ldots 10^{-9}$. The serially diluted water samples were spread plated onto SDA plates with the addition of chloramphenicol in order to minimize bacterial contamination and addition of cyclohexamide in order to reduce the contamination of saprophytic fungi. The inoculated SDA plates were incubated at room temperature for 21 days.

\section{Collection of plant materials and extract preparation}

The bulbs of Allium sativum and the leaves of Cymbopogon citratus were collected from different places of Chennai. The fresh leaves of Cymbopogon citratus and bulbs of Allium sativum were washed with distilled water to remove unwanted foreign materials like soil and dusts. Then the plant materials were dried under shade at room temperature without direct exposure of sunrays. The plant materials were coarsely grounded using mechanical device. Solvent extracts were prepared by soaking $10 \mathrm{~g}$ of powder (leaves of Cymbopogon citratus)/paste (bulbs of Allium sativum) successively in $100 \mathrm{ml}$ of respective solvents as detailed using Soxhlet appratus. Leaves of Cymbopogon citratus and bulbs of Allium sativum (garlic) were extracted with various solvents (ethanol, ethyl acetate and aqueous for Cymbopogon citratus, and ethyl acetate chloroform and aqueous for Allium sativum). The extracts were stored at $4^{\circ} \mathrm{C}$ in closed container until use.

\section{Susceptibility test}

One $\mathrm{ml}$ of the plant extract was incorporated into one $\mathrm{ml}$ of Sabouraud's dextrose (SD) broth and was serially diluted so as to achieve concentrations ranging from $1000 \mu \mathrm{g} / \mathrm{ml}$ to $31.25 \mu \mathrm{g} / \mathrm{ml}$ respectively. $20 \mu \mathrm{l}$ of fungal inoculum was added to each tube and incubated at room temperature for 21days. Suitable controls were included. Sabouraud's dextrose broth with $20 \mu$ of inoculum served as positive control whereas, SD broth alone served as negative control. The whole setup in duplicate was incubated at room temperature for 21 days.

\section{Determination of Minimum Inhibitory Concentration (MIC)}

The minimum inhibitory concentration is a measure of the sensitivity of microbes to antibiotics or antifungals (antimicrobials). Organisms are tested for growth in various concentrations of antibiotic. This allows microbiologists to see which concentration (MIC) of antimicrobial will be effective against the pathogen. MIC was determined by adding $1 \mathrm{ml}$ of SD broth in 6 tubes. One $\mathrm{ml}$ of lemon grass leaf extract and garlic bulb extract was added in the first tube which gives the concentration of $1000 \mu \mathrm{g} / \mathrm{ml}$. It was further diluted until the concentration lowers to $31.25 \mu \mathrm{g} / \mathrm{ml}$ respectively. Then $20 \mu 1$ of standard fungal culture was added to each tube and inoculated at room temperature for 21 days. Respective controls were also maintained without extracts. Microsporum canis and Microsporum gypseum were used for the study, since they were found to be the predominant species in the water samples.

\section{Determination of Minimum Fungicidal Concentration (MFC)}

Minimum fungicidal concentrations were determined for each isolate medium drug combination. MFCs were defined as the lowest drug dilutions that yielded $<3$ colonies (approximately 99 to $99.5 \%$ killing activity).

\section{Results and discussion}

Sixty different water samples were collected and examined for dermatophytes from different places of Tamil Nadu, which included sewage water, swimming 
pool, pond water and river water. Out of the 60 samples 19 were isolated as Microsporum canis, 18 as Microsporum gypseum, 9 as Microsporum nanum, 6 as Microsporum persicolor and 4 were isolated on SDA medium as Microsporum audouinii (Table 1). Microsporum species was inhibited by ethanolic extract of lemongrass leaves in the concentration of $250(\mu \mathrm{g} / \mathrm{ml})$, whereas by ethyl acetate extract in the concentration of $62.5(\mu \mathrm{g} / \mathrm{ml})$ and the aqueous extract in the concentration of $1000(\mu \mathrm{g} / \mathrm{ml})$ (Table 2). Microsporum species was inhibited by chloroform extract of garlic bulb in the concentration of $250(\mu \mathrm{g} / \mathrm{ml})$, whereas by ethyl acetate extract in the concentration of $125(\mu \mathrm{g} / \mathrm{ml})$ and the aqueous extract in the concentration of $500(\mu \mathrm{g} / \mathrm{ml})$ (Table 3). Since the ethyl acetate extract of both the plants showed least MIC and MFC against Micropsorum species, combined activity of ethyl acetate extract of Cymbopogon citratus leaves and Allium sativum bulb has been tested and results are given in Fig. 1. Combination of ethyl acetate extracts had greater activity against Microsporum spp. Microsporum species was inhibited by combined activity of ethyl acetate extracts of Cymbopogon citratus and Allium sativum in the concentration of $62.5(\mu \mathrm{g} / \mathrm{ml})$ (Fig. 1).

Table 1. Number of Microsporum spp. isolated and identified from different samples.

\begin{tabular}{llllll}
\hline \multirow{2}{*}{ S. No. } & \multirow{2}{*}{ Species } & \multicolumn{2}{l}{ No. of dermatophyte isolates } & & \\
\cline { 3 - 6 } & Sewage & Swimming pool & Pond & Lake & Total \\
\hline 1 & Microsporum canis & 7 & 6 & 2 & 4 \\
2 & Microsporum gypseum & 8 & 6 & 3 & 19 \\
3 & Microsporum nanum & 4 & 3 & 1 & 18 \\
4 & Microsporum audounii & 3 & 2 & 1 & 9 \\
5 & Microsporum persicolor & 3 & 1 & - & - \\
\hline
\end{tabular}

Table 2. MIC and MFC of Cymbopogon citratus leaf extracts against Microsporum isolates.

\begin{tabular}{|c|c|c|c|c|c|c|c|}
\hline \multirow{2}{*}{ S. No. } & \multirow{2}{*}{ Organism } & \multicolumn{2}{|c|}{ Ethyl acetate $(\mu \mathrm{g} / \mathrm{ml})$} & \multicolumn{2}{|c|}{ Ethanol $(\mu \mathrm{g} / \mathrm{ml})$} & \multicolumn{2}{|c|}{ Aqueous $(\mu \mathrm{g} / \mathrm{ml})$} \\
\hline & & MIC & MFC & MIC & MFC & MIC & MFC \\
\hline 1. & Microsporum gypseum & 62.5 & 62.5 & 250 & 250 & 1000 & 1000 \\
\hline 2. & Microsporum canis & 125 & 125 & 250 & 250 & 1000 & 1000 \\
\hline
\end{tabular}

Table 3. MIC and MFC of Allium sativum bulb extracts against Microsporum isolates.

\begin{tabular}{llllllll}
\hline \multirow{2}{*}{ S. No. } & \multirow{2}{*}{ Organism } & \multicolumn{2}{c}{ Ethyl acetate $(\boldsymbol{\mu g} / \mathbf{m l})$} & \multicolumn{2}{c}{ Chloroform $(\boldsymbol{\mu g} / \mathbf{m l})$} & \multicolumn{2}{c}{ Aqueous $(\boldsymbol{\mu g} / \mathbf{m l})$} \\
& & MIC & MFC & MIC & MFC & MIC & MFC \\
\hline 1. & Microsporum gypseum & 125 & 125 & 250 & 250 & 500 & 500 \\
2. & Microsporum canis & 62.5 & 62.5 & 250 & 250 & 500 & 500 \\
\hline
\end{tabular}

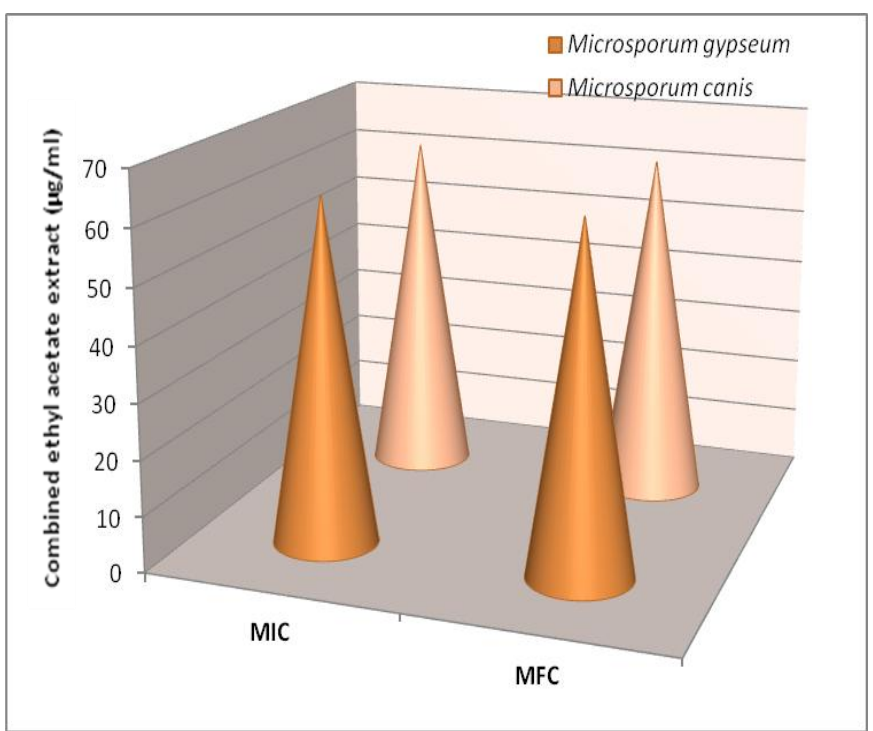

Fig. 1: MIC of combined ethyl acetate extracts of Allium sativum and Cymbopogon citratus.
The present study revealed that out of 60 water samples collected, 40 species of keratinophilic and nonkeratinophilic fungi were isolated from different water samples such as sewage water, pond water and river water. In our present study we isolated Microsporum canis, Microsporum gypseum, Microsporum nanum, Microsporum persicolor and Microsporum audonii. The total of 19 isolates of Microsporum canis, 18 isolates of Microsporum gypseum, 9 isolates of Microsporum nanum and 6 of Microsporum persicolor was isolated from different water samples. From sewage water samples, Krishnaveni et al. (2016) isolated Microsporum canis, Microsporum gypseum, Microsporum nanum. Microsporum gypseum was inhibited by chloroform extract in the concentration of $250(\mu \mathrm{g} / \mathrm{ml})$, whereas by ethylacetate extract in the concentration of $125(\mu \mathrm{g} / \mathrm{ml})$ and the aqueous extract in the concentration of 500 $(\mu \mathrm{g} / \mathrm{ml})$. Ethyl acetate extract was found to have higher activity than the chloroform and aqueous extract against 
both the organism Microsporum canis and Microsporum gypseum in the present study. According to Cavallito et al. (1974) who proposed that Allium sativum was found to be most effective and also completely checking the mycelial growth of Microsporum gypseum at $10 \%$ concentration showing $83.09 \%$ inhibition in ethyl acetate extract. Ethyl acetate extract was found to have higher activity than the ethanol and the aqueous extract against both the fungi, Microsporum canis and Microsporum gypseum. The antifungal activities of Cymbopogon citratus essential oils on Microsporum canis had stronger inhibitory at the concentration of $67.8 \%$ according to Elkhair (2014). In the present study, Microsporum gypseum was inhibited by ethyl acetate extract of combined activity of lemon grass and garlic bulb in the concentration of $62.5(\mu \mathrm{g} / \mathrm{ml})$. Guevara et al. (1983) was discussed and studied the minimum inhibitory concentration of Allium sativum on Microsporum gypseum and Microsporum canis with the combinational activity of Nigella sativa and Lawsonia alba. Of these three extracts Allium sativum inhibited the growth by 47.5-100\% in ethyl acetate solvent and Nigella sativa inhibited the growth by $35.13-100 \%$ and Lawsonia alba inhibited the growth by $21.87-100 \%$. Least MIC and MFC recorded for combined ethyl acetate extracts of Allium sativum and Cymbopogon citratus extracts in the present study might be due to the synergism of extracts which put forth enhanced activity as reported against pathogenic bacteria (Karmegam et al., 2008; Vigneshwari et al., 2014).

\section{Conclusion}

The results obtained from this work showed that plant extracts of Cymbopogon citratus and Allium sativum exhibit antifungal effects against Microsporum spp. This study also supports the traditional medicinal use of different plant extracts in treating different infections caused by pathogenic fungi either by using single or combined form. Natural plant-derived fungicides may be a source of new alternative active compounds, in particular with antifungal activity.

\section{Conflict of interest statement}

Authors declare that they have no conflict of interest.

\section{References}

Ajello, L., 1974. Natural history of the dermatophytes and related fungi. Mycopathol. Mycol. Appl. 53, 93-110.

Barisic Drusko, V., Rucevic, I., Bilijan, D., Jukic, Z., 2003. Epidemiology of dermatomychosis in the eastern Croatia today and yesterday. Coll. Antropol. 27, 11-17.

Joshi, B., Sah, G. P., Basnet, B. B., Bhatt, M. R., Sharma, D., Subedi, K., Pandey, J., Malla, R., 2011. Phytochemical extraction and antimicrobial properties of different medicinal plants: Ocimum sanctum (Tulsi), Eugenia caryophyllata (Clove), Achyranthes bidentata (Datiwan) and Azadirachta indica (Neem). J. Microbiol. Antimicrob. 3(1), 1-7.

Cavallito, V. J., Buck, J. S., Luter, C. M., 1974. Allicin, the antibacterial principle of Allium sativum, II. Determination of chemical structure. J. Amer. Chem. Soc. 66, 1940.

Emmons, C.W., 1934. Dermatophytes-natural grouping based on the form of the spores and accessory organs. Arch. Dermatol. Syphil. 30(3), 337-362.

Elkhair, E. K. A., 2014. Antidermatophytic activity of essential oils against locally isolated Microsporum canis-Gaza Strip. Natural Sci. 6, 676-684.

Gbile, Z. O., 1986. Ethnobotany, taxonomy and conservation of medicinal plants. In: State of Medicinal Plants Research in Nigeria (Ed.: Soforowa, A.), Ibadan University press, Ibadan. pp.126-130.

Gunasingh, C. B. G., Nagarajan, S., 1981. Flavonoids of Cymbopogon citratus. Indian J. Pharm. Sci. 43, 115.

Guevara, B.Q., Solevilla, R. C., Mantaring, N. M., Remulla, R. A., Santos, P.C., 1983. Antifungal properties of Allium sativum grown in Phillipines. Acta Manilana. 22, 1-14.

Jaber, M. A., Al-Mossawi, A., 2007. Susceptibility of some multiple resistant bacteria to garlic extract. Afr. J. Biotechnol. 6(6), 771-777.

Kacprzak, M., Neczaj, E., Okoniewska, E., 2005. The comparative mycological analysis of waste water and sewage sludges from selected waste water treatment plant. Desalination. 185, 363-370.

Karmegam, N., Karuppusamy, S., Prakash, M., Jayakumar, M., Rajasekar, K., 2008. Antibacterial potency and synergistic effect of certain plant extracts against food-borne diarrheagenic bacteria. Int. J. Biomed. Pharmaceut. Sci. 2(2), 88-93.

Krishnaveni. G., Banu Rekha. C., Rajendran. P., 2016. Incidence of Microsporum species from different soil and water samples from South Tamil Nadu. Asian J. Multidiscip. Stud. 2, 223-227.

Vigneshwari, C., Nagaraj, R., Karmegam, N., 2014. Synergistic anti-Staphylococcus aureus (methicillin resistant) activity of ethnomedicinal plants from Shevaroy hills (Eastern Ghats), south India. Int. J. Curr. Res. Biosci. Plant Biol. 1(2), 51-59.

\footnotetext{
How to cite this article:

Krishnaveni, G., Banu Rekha, C., Rajendran, P., Nithyakalyani, V., Vithiyavani, P., 2016. Antidermatophytic potential of selected medicinal plants against Microsporum species. Int. J. Curr. Res. Biosci. Plant Biol. 3(5), 102-106. doi: http://dx.doi.org/10.20546/ijcrbp.2016.305.016
} 